\title{
Learning Assistants' Development of Physics (Teacher) Identity
}

\author{
Eleanor W. Close, Jessica Conn, and Hunter G. Close \\ Department of Physics, Texas State University, San Marcos, TX 78666
}

\begin{abstract}
The physics department at Texas State University is developing a Learning Assistant (LA) program with reform-based instructional changes in our introductory course sequences. We are interested in how participation in the LA program influences LAs' identity both as physics students and as physics teachers; in particular, how being part of the LA community changes participants' self-concepts and their day-to-day practice. We analyze written artifacts from program applications, reflections, and evaluations; our analysis of self-concepts is informed by the identity framework developed by Hazari and colleagues [1,2] and our analysis of practice is informed by Lave and Wenger's theory of Communities of Practice [3,4]. Preliminary experience suggests that engagement in the collaborative physics education community elements of the LA program blurs the distinction between learner and teacher practice and increases LAs' engagement in negotiation of meaning in both contexts.
\end{abstract}

Keywords: Learning assistants, physics identity, community of practice, teacher preparation, teacher recruitment. PACS: 01.40.Fk, 01.40.Ha, 01.40.jc

\section{INTRODUCTION}

The physics department at Texas State University has recently implemented a Learning Assistant (LA) program based on the model developed at CU-Boulder [5] and supporting course reform in our introductory calculus-based physics sequence. LAs are recruited from undergraduate STEM majors, attend weekly preparation sessions, and assist instructors with interactive instructional activities during regular class time. In addition, new LAs take a course in physics cognition and pedagogy, and some LAs work in the newly-established Physics Help Center and grade papers. After a program pilot in spring semester 2012, the LA program was implemented in all sections of the introductory mechanics course in fall 2012, and expanded to include one section of introductory electricity and magnetism in spring 2013. LAs have been hired for fall 2013.

In this paper we analyze the LA experience empirically in terms of the existing theoretical frameworks of communities of practice and physics identity, building on our prior similar analysis of the LA model [6]. Specifically, we examine written data sources for evidence of whether participation in the LA program has affected elements of LAs' identity, and if so, in what ways and through what program elements.

\section{THEORETICAL BACKGROUND}

In this section, we give a brief overview of relevant elements of the two theoretical frameworks used in our analysis. In the following sections, we build a correspondence between factors in the physics identity framework and community of practice theory, and use this blended theory to analyze written artifacts produced by LAs.

\section{Identity in Practice}

Lave and Wenger $[3,4]$ describe participation in communities of practice and development of identity as deeply intertwined. Membership in a community of practice requires negotiation with other members of how to engage together in the shared practice - how to relate to others, and how to understand the meaning of events and interactions in the context of the community. In this view, identity is not an inherent or fixed quality of a person, but rather a process of continuous re-negotiation - "a constant becoming" [4, p. 154]. Within this framework, Wenger [4] identifies five characterizations of identity, four of which we find particularly relevant to our current study: identity as negotiated experience, as community membership, as learning trajectory, and as nexus of multimembership. (Identity as a relation between the local and the global did not appear to be a strong emergent theme from our data set.) 
Individuals are members of multiple communities of practice. Building on our prior work [6], we focus this analysis on two communities of which LAs are members: the community of undergraduate STEM majors, engaged in the joint enterprise of negotiating required coursework and obtaining a STEM degree; and the community of physics instructors, engaged in the joint enterprise of supporting students in their learning of physics concepts and skills.

\section{Physics Identity}

Hazari and colleagues [1] describe a theoretical framework for physics identity composed of four dimensions: personal interest, student performance, competence, and recognition by others. They used data drawn from the PRiSE Project, in which several thousand first-year college students responded to survey questions designed to characterize their interests and experiences in science. The nature of the data set means that the assessment of all dimensions of physics identity was based on self-report; e.g., the dimension competence can be described as "belief in ability to perform required physics tasks." In later work, using a factor analysis of survey data from over 6500 college students drawn from the SaGE Project, Lock, Hazari, \& Potvin [2] found that the dimensions of performance and competence formed a single factor; the theoretical framework was therefore simplified to three dimensions. Regression models from these studies show that the physics identity construct strongly predicts intended choice of a career in physics.

\section{METHODS}

Data for this study are drawn from two forms of writing produced by LAs: program applications, and written programmatic feedback.

Students who wish to be LAs must apply near the end of each semester in order to serve as an LA the following semester. New and experienced LAs complete different applications. The Returning LA application includes open-ended questions such as "Why do you want to continue to be an LA?" "What is your opinion of your performance as an LA this semester?" and "What have you learned from being an LA so far?"

At the end of each semester, the weekly time usually reserved for instructional preparation is used for reflection and discussion, with the explicit goal of soliciting feedback from LAs in order to make improvements to the program. In both fall 2012 and spring 2013, LAs were asked to spend some time writing responses to questions about positive and negative aspects of their experiences in the program; these responses were collected by one of the LAs and held by the department administrator until after course grades were due, in the manner of course evaluations, in order to encourage honest constructive criticism.

Due to space constraints, we focus here on data from three LAs, with pseudonyms Leah, Mike, and Brooke. The character of their written comments is typical of what we see from returning LAs; we chose to present data from the three students who most clearly articulated the difference that participation in the LA program made to their experience of being a physics person, student, and instructor.

\section{ANALYSIS}

In this section we build a correspondence between factors in the physics identity framework and communities of practice theory. The former is rigorously predictive but not causal, while the latter is causal but not rigorously predictive. Thus, the link between the two should help the physics community create effective interventions that positively influence physics identity for students. We then examine the data described above for evidence of the effect of the LA Program on participant identities, using the theoretical lens of physics identity as described in each section.

\section{Negotiated Experience and Recognition}

Identity as negotiated experience is the process of making meaning from the encounters and experiences of participation in a community of practice. Wenger summarizes this in the following way: "We define who we are by the ways we experience our selves through participation as well as by the ways we and others reify our selves." [4, p. 149]. The meaning we make of our experience is shaped by how others respond to us - how we "encounter our effects on the world" - and by the characteristics and relations the community values and reifies. The physics identity dimension of (self-reported) recognition, as measured through survey items such as "My physics teacher sees me as a physics person" and "my friends see me as a physics person" [2], describes an element of this characterization of identity. Self-image is a component of identity in this characterization, but not the entirety: self-image is a reification involving labels such as "physics person" and "Learning Assistant," and identity through negotiated experience encompasses the interaction of these reifications with the experiences of participation in the community.

The responses of participants to questions on the Returning LA application reflect this negotiation: 
"I've also found a real passion for teaching through this program. Previously, I may not have considered teaching after I obtain my degree but my experiences in the Learning Assistant program have made me realize how rewarding it is to help students grasp ideas that were once out of their reach." - Leah

"I am naturally shy and introverted person; so, at first, it was a little difficult for me to break out of my shell. Furthermore, not being a physics major, I didn't feel I had the credibility to instruct students in physics concepts. However, as I began talking with the students and other LAs, I immediately realized how comfortable I feel teaching/talking with my peers." - Mike

These statements describe experiences of recognizing the effects of interactions with others, both on the others and on the self. The phrases "found a real passion for teaching" and "realized how comfortable I feel teaching/talking" indicate shifts in these LAs' perceptions of self; Leah's description of feeling rewarded by helping students learn indicates a new sense of her effect on others. In some cases, LAs refer explicitly to the impact of recognition received from peers or near-peers:

"[A student] came up to me after the test and said he received a score of 105, and credited this score exclusively to my discussion with him on the day preceding the test. That was probably about the proudest I have ever felt in my life." - Mike

Another LA experienced an expanded sense of her access to other members of the physics community:

"One of the things I really enjoyed about [being an LA] was that I became way more involved in the department and I feel like I have a larger network of help if I need it because of it." - Brooke

This is particularly notable because Brooke was already an upper-level physics major when she began her participation in the LA program. Brooke wrote this in December 2012 on her application for spring 2013; she made a similar statement in her written programmatic feedback in late April 2013:

"As a physics major, when I was just a student, I was too self-conscious to approach a professor to ask questions. But as part of a community, that includes my professors, I can approach them with questions, no problem. Also, building a community of student peers has also increased my academic performance."

In addition to showing a change in Brooke's sense of self in relation to those around her, this quote has two additional features: it shows the close relationship between negotiated experience and community membership, and it illustrates the importance of the experience of membership in both student and instructor communities of practice. These features will be addressed in the following sections.

\section{Community Membership and Competence}

Community membership defines identity through the forms of competence developed and valued by participants in the community. This includes the ways in which members of the community interact with each other and work together; the perspectives and interpretations they share; and the ability to make use of a shared repertoire of language, tools, and other resources. Community membership shapes how we look at the world, how we relate to others, and what we know how to do. This encompasses the physics identity dimension of (self-reported) competence/ performance, which is measured through survey items such as "I understand concepts I have studied in this subject" and "Others ask me for help in this subject" [2]. "Full members" of a community of practice feel competent and comfortable.

We have already seen evidence that Brooke's sense of competence as a student has been changed through her altered experience of membership in the community of STEM students ("building a community of student peers has also increased my academic performance"). She also identifies a new sense of comfort in interactions with faculty:

"Being an LA has greatly increased my ability to interact with my professors. ... Joining the LA program has definitely made me feel like a part of the department, not just a student."

Mike expresses a similar feeling with respect to the community of STEM majors:

"Considering we almost always had group discussions, [the pedagogy] course also helped me feel more comfortable around the other LAs and the students in the [mechanics] classes."

On her application for fall 2013, Leah demonstrates that she is both familiar and comfortable with elements of the instructional community's shared repertoire:

"In the past two semesters of being an LA, I've learned how to communicate more effectively to people... If someone doesn't understand a concept when I explain it verbally, I can draw them a picture or a diagram instead. If they can't verbalize what they're thinking themselves, sometimes handing over a marker so they can draw something out for me will help me understand where they're at in their understanding of the material."

In addition to making her a more skilled instructor, comfort with this repertoire crosses over into the work of the STEM major community, which Leah recognizes: 
"Being an LA has made me a more competent person all around."

Here we see again the close relationship between community membership and negotiated experience: through her increasingly competent participation in the community, Leah's sense of self has changed to include the reified identity "competent person."

\section{Learning Trajectory and Personal Interest}

As described above, identity is constantly renegotiated; changes in identity over time build a sense of trajectory - a sense of where we have been and where we are going. Identity as learning trajectory incorporates past identities and possible futures into making meaning of the present. Participation in a community impacts an individual's identity only to the extent that the practice of the community incorporates that person's past and fits into a valued future; trajectory influences what elements of participation are perceived as important and what are marginal. This encompasses the physics identity dimension of personal interest, which is measured through survey items such as "I enjoy learning this subject" and "I am interested in learning more about this subject" [2].

On his initial application to the LA program, Mike described a possible future he believed would be positively influenced by participation:

"For me, I think that this would be an awesome opportunity to test my ability as a teacher. Since I started at Texas State, I have dreamed of one day becoming a professor."

His subsequent applications continue to refer to this dream, and to the value he sees in the LA experience for supporting that possibility. Leah, on the other hand, has experienced a significant shift in what she perceives as a possible future:

"After having experience teaching this semester, I am considering working as a K-12 teacher after college because I've enjoyed how rewarding teaching has been this past semester."

On her initial application, Leah listed her major as electrical engineering and expressed interest in a biomedical engineering career; a few months later, she switched her major to physics, and she is now considering a career in K-12 teaching.

\section{Nexus of Multimembership and Physics (Teacher) Identity}

As stated above, individuals are members of multiple communities of practice. Identity as nexus of multimembership is defined by the work of reconciling forms of membership in different communities. In previous analysis [6], we describe the LA program as creating an overlap between the community of STEM majors and that of physics instructors, such that LAs are members of both communities and the shared practices improve the functioning of each one. Here we extend this analysis to include the impact of multimembership on LAs' construction of identity. The quotes above show impact on LAs participation in both communities; they experience increased competence in both, and describe changes in their level comfort in both. We hypothesize that the overlap of these communities created by the LA program allows LAs to easily reconcile their forms of membership in each community, to the extent that the distinction between the two communities becomes blurred: participation in the instructional community increases physics student competence, and vice versa.

\section{IMPLICATIONS \& FUTURE WORK}

The analysis presented here suggests that participation in the LA program impacts LAs in ways that support both stronger "physics person" identity and stronger "physics teacher" identity, and that these identities may be easily reconciled into a coherent physics identity. The increased feeling of comfort in interactions with peers, near-peers, and faculty seems to be an important component of identity development and reconciliation. We have some evidence that this increased comfort is facilitated particularly well by informal interactions in preparation sessions and in the Physics Help Center. Further work is needed to confirm this and to identify what elements of the LA program and forms of participation in it contribute most substantively to identity development.

\section{ACKNOWLEDGMENTS}

This work and the Texas State University Physics Learning Assistant Program are supported in part by NSF grant DUE-1240036.

\section{REFERENCES}

1. Z. Hazari et al., J. Res. Sci. Teach. 47 (8), 978-1003 (2010).

2. R. M. Lock, Z. Hazari, \& G. Potvin, in AIP Conf. Proceedings 1513 (PERC 2012), 2013, pp. 262-265.

3. J. Lave \& E. Wenger, Situated learning: Legitimate peripheral participation. (Cambridge Univ. Press, 1991).

4. E. Wenger, Communities of Practice: Learning, Meaning, and Identity. (Cambridge Univ. Press, 1998).

5. V. Otero, S. Pollock, \& N. Finkelstein, Am. J. Phys. 78 (11), 1218-1224 (2010).

6. E. Close, H. Close, \& D. Donnelly, in AIP Conf. Proceedings 1513 (PERC 2012), 2013, pp. 106-109. 